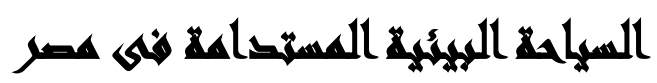

[0]

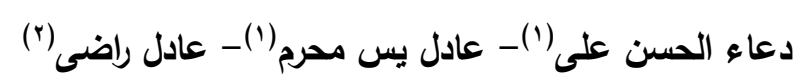

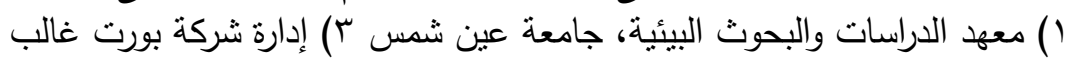

\section{المستخليك}

لكي شُتخدم الإمكانيات والمقومات المتاحة بالطريقة النى تعمل علي دفع عجلة التنمية

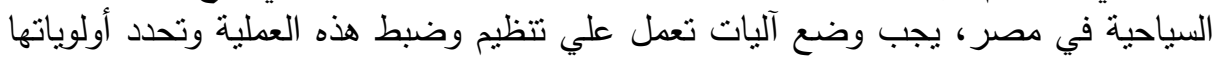

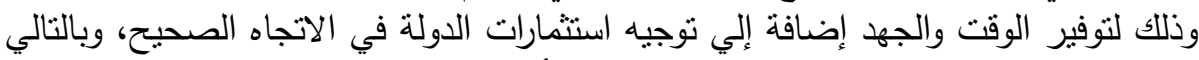

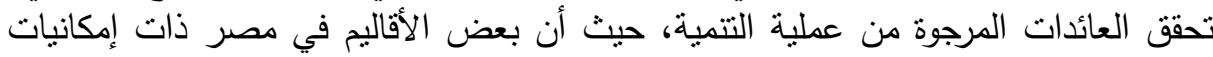
ومميزرت تفوق العديد من الأقاليم الاخري لكنها تفتقر أيضا إلي العديد من العناصية دمر الآخري الضرورية والهامة لعملية التتمية. ولاختيار الأقاليم للتتمية السياحية أهمية في عطلية التتمية فليس كل إقليم يصلح اللتمبية

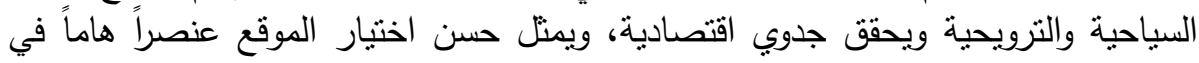
علية التتية نفسها.

\section{axis}

عرف الإنسان السفر والتتقل منذ القدم وارتاد الأماكن المأهولة لاكتثافها حيث أن

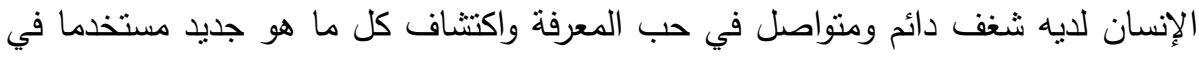

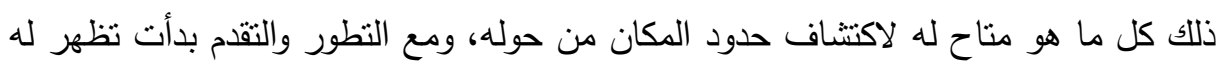
دوافع وميول متجدة نحو الرحلة والتزحال خصوصا بعد تطور وسائل النقل والمواصلات

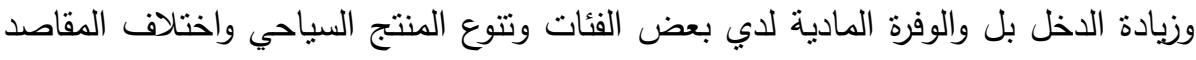

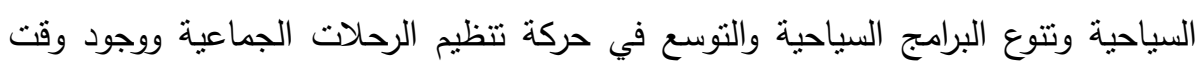
فراغ. والرغبة في التزفيه والتزويح بعد تعقد الحياة وصعوبتها. (دعبس، 2003 فركة). 


\section{And ILan}

1- تتسم معظم المنثآت السياحية بضعف الهوية العربية والمحلية فى تصميمها، وعدم

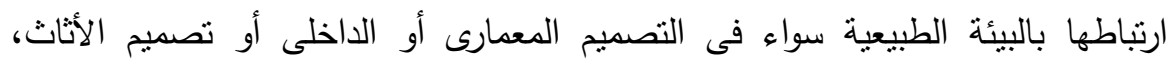

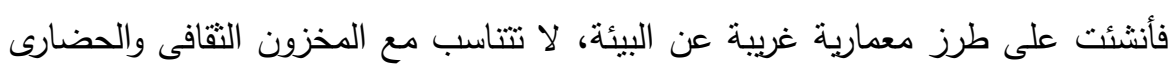
للمكان وفى غير نوافق كافٍ مع البيئة الطبيعية المحيطة بها ولا مناخها.

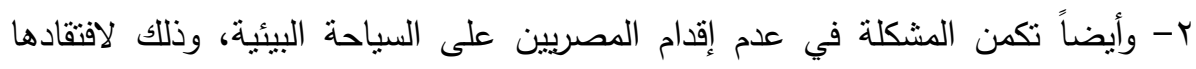
للاعاية والثقافة اللازمة إما عن قصد من المسؤولين مع عدم اظهار الامكانيات الصادقة

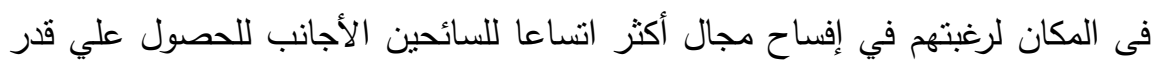
أكبر من المكاسب المادية مقارنة بما يمكن الحصول عليه من المصرئ العرين.

\section{And المهal}

$$
\text { تكمن أهمية البحث في: - أنه }
$$

1- انه يعتبر خطوه نحو دعم مفهوم العمارة البيئية للمنشآت السياحية من خلال إمكانية

$$
\text { توظيف الخامات الطبيعية. }
$$

r- محاولة إضفاء طابع معمارى بيئي مميز للمنتجعات السياحية يحقق الترابط بين العمارة

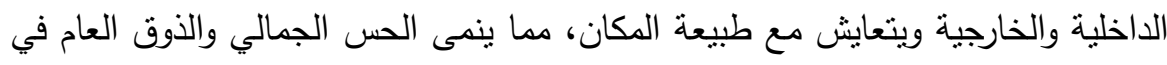
المجتمع ويزيد من عناصر الجذب السياحي للمنتجعات السياحية.

\section{Aats}

زمانيا": وهو فترة إجراء البحث الميداني على المنتجعات السياحية ودراسة استخدام الخامات الطبيعية في العمارة الداخلية في أواخر القرن العشرين وأوائل القرن الحادي والعشرين.

مكانيا": دراسة استخدام الخامات الطبيعية في العمارة الداخلية في مصر . مفهوما": وهو الاستلهام من العناصر الطبيعية وكيفية الاستفادة منها في التصميم الداخلي البيئي للمنتجعات السباحية المقترحة. 


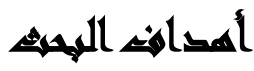

1- التزكيز على توضيح أهمية نوافق المبانى السياحية مع البيئة الطبيعية بما تتضمنه من

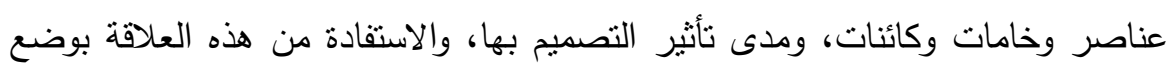

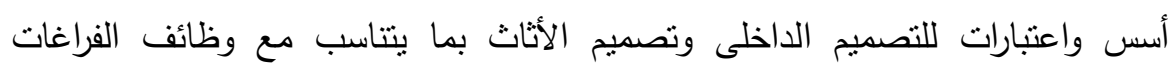

$$
\text { واحتياجات الإنسان. }
$$

ץ- توضيح وإمكان استغلال التراث البنائى المناح فى المنطقة السياحية بعد تتاوله بالتزميم والتعديل.

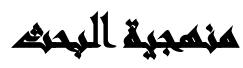

المنهج التحليلي: يقوم على وصف الظاهرة وجمع البيانات والمعلومات عنها ويتم ذلك من خلال دراسة الموارد الطبيعية مع عرض وتحليل ووصف نماذج من أعمال التصميم الداخلي. المنهج التطبيقي: تطبيق التصميم البيئي على العمارة الداخلية المحلية. الفندق البيئي (الايكولودج) كأحد الحلول المعمارية لتنمية السياحة البيئية في مصر : الفنادق لئني

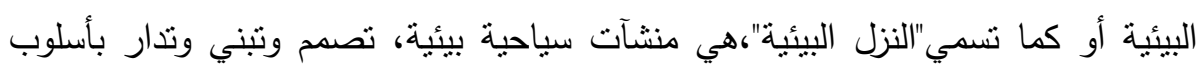
بساهم ويدعم عمليات الحفاظ علي الموارد الطبيعية والثقافية.

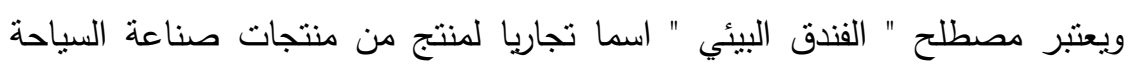
يستخدم لتحديد هوية نوع من المنشآت السياحية المعتمدة علي عنصر الطبيعة، فأهم ما يعنينا بالدرجة الأولى هو خصائص المكان، الطبيعة الوعرة، عوامل الجذب الثقافية وأساليب إدارة

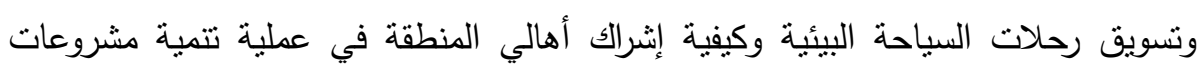
الفندق البيئي ولذلك فان مشروع الفندق البيئي يؤدي إلى رفع القيمة الاقتصادية للموارد

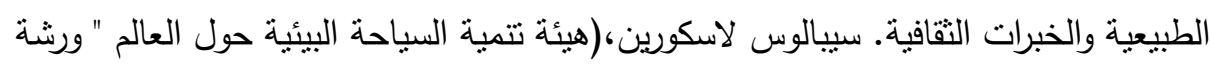
عمل الفنادق البيئية في القصير ، (هيئة التتمية السياحية، مصر لو9 199 م"). ويمكن تفهم الايكولودج في السياق المصري علي أنه نوع جديد من المباني السياحية

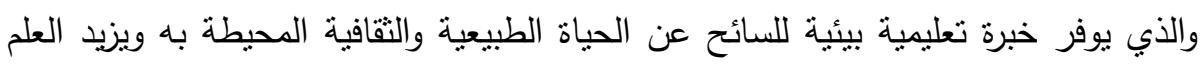

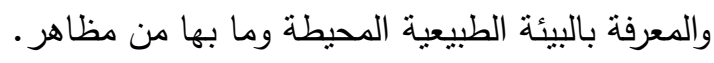

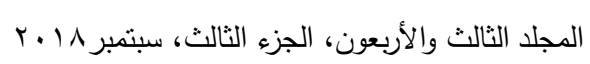


ويتطلب تصميم مشروع فندق بيئي" ايكولودج" (Eco-lodge) إنباع أسلوب معماري بطلق عليه تعبير "ايكوديزاين" (Eco-design) ويعتمد هذا الأسلوب علي ثلاثة مبادئ، يجب أن تؤخذ في الاعتبار عند التنفيذ، وهذه المبادئ هي:

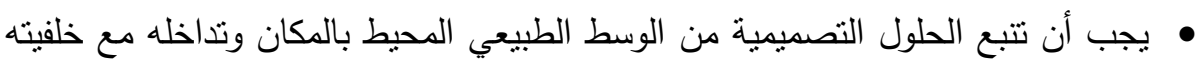

• يجب أن تشارك الجماعات المحلية في عملية التصميم والتتفيذ للاستفادة من خبراته المتراكمة عبر سنوات عديدة في هذه المجالات.

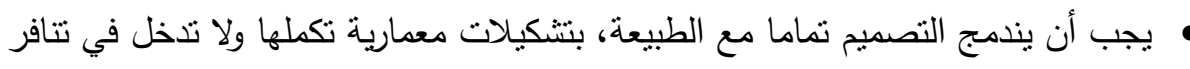

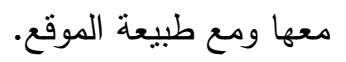
ومما سبق يتبين أن العنصر الأساسي في إنثاء الفندق البيئي هو الوصول إلى عملية

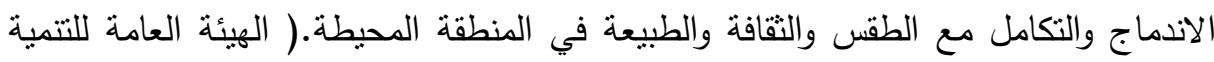

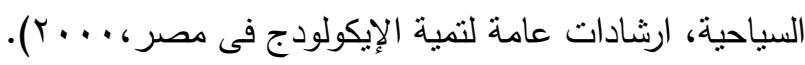
الاعتبارات التصميمة والتخطيطية للفندق البيئي Eco-lodge : من واقع تعريف الفندق

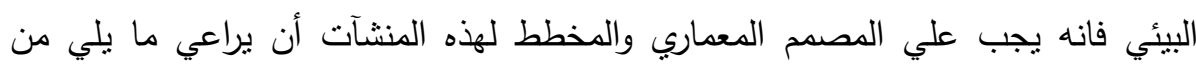
اعتبارات: ويمكن تقسيم تلك العناصر طبقاً للتالي: بيئة محيطة:

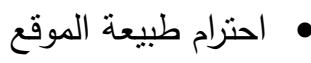
• التقليل قدر الإمكان مما يمكن أن يحدثه المنتج من تلويث للبيئة الطبيعية( هواء، ماء،

• ألا يسبب المنتج المعماري أي ضرر بالموارد التاريخية والأثرية للمنطقة المقام بها.

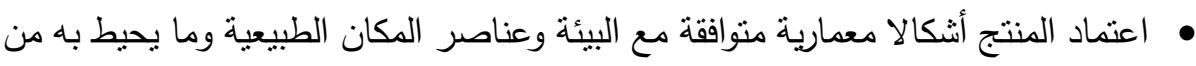
مباني محلية بحيث لا يسبب تتافرا مع الجمال الطبيعي للتضاريس الجغرافية.

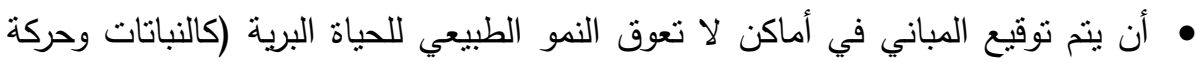
الكائنات الأخرى في المكان) مع محاولة الاندماج مع ع عناصر البيئة الطبيعية بطريقة لئية 
سهله من خلال استخدام الألوان الهادئة في المباني والقريبة من ألوان تلاك العناصر

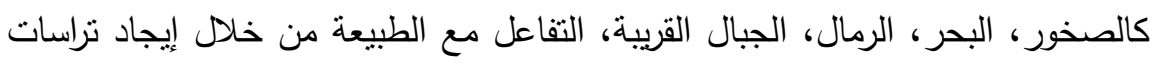

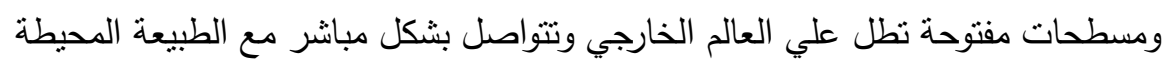

$$
\text { بصريا وحركيا. }
$$

أن يثري المنتج البيئة الحضارية ويحافظ علي موروثها الحضاري ولا يكون سببا في ضياع طابع المنطقة.

\section{تعبئة متوافقة:}

• • احترام الموارد الثقافية مع الإقلال من المؤثرات السلبية للتتمية. • ضمان استراتيجية لادخار الطاقة مع تلافي استخدام خامات تتطلب طاقة مكثفة، وضارة الإنة بيئياً وذات ناتج عالي من المخلفات مع ضرورة الاستفادة من الخامات والمواد المحلية لادية سواء في أعمال البناء أو أغراض الديكور والفرش للوحدات والمنشآت المختلفة وأساليب التشطيب. • يراعي التصميم المعماري استقبال المعاقين جسديا وحسيا، كما يجب التوازن في استعمال المبني بين مختلف أنواع الزوار والمستخدمين له. • براعي تقسيم المشروع إلى مراحل تتفيذية بغرض مراقبة نأثيراته علي الموارد الطبيعية

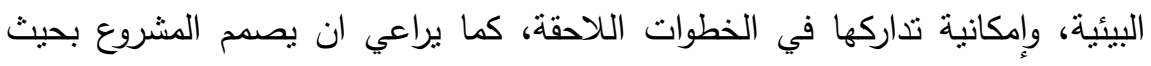

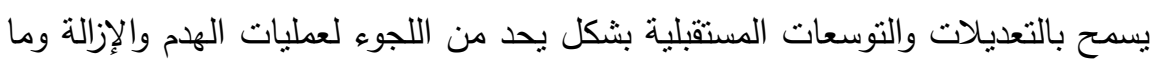
ينتج عنها من مخلفات، وذللك باستخدام مواد تثقبل بسهولة عملية إعادة الاستخدام.

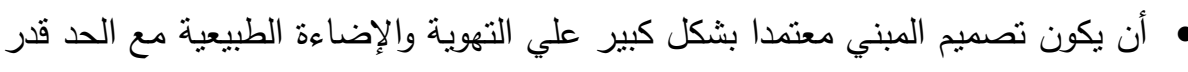
الإمكان من التهوية والإضاءة الصناعية، كما يجب تجنب استخدام تكييف الهواء الصناعي والاهتمام بالمعالجات المناخية الطبيعية مثل : استخدام ملاقف الهواء في أسطح

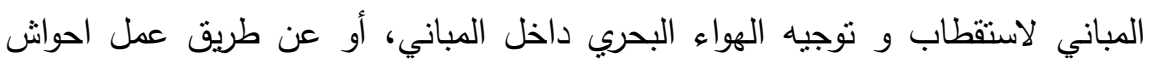
وأفنية داخل الوحدات تعمل علي توفير التهوية الجيدة للواجهات الداخلية المطلة عليها. • استخدام آليات التصميم البيئي ( طاقة شمسية ورياح ومياه.... الخ). 


\section{مواد من طيبعة المكان:}

• استخدام مواد بناء محلية متجددة المصدر مع استخدام تكنولوجيا مبسطة ملائمة

للاحتباجات الوظيفية

• الاقتصاد قدر الإمكان في مساحات المباني للحد من التأثيرات السلبية، من خلال استخدام

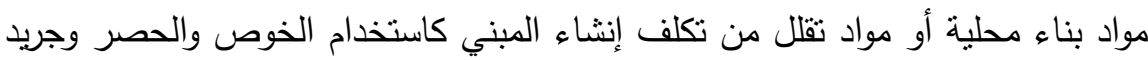
النخيل في المناطق التي تتميز بنمو النخيل بكثافة.

• أن يتم توقيع المباني في أماكن لا تعوق النمو الطبيعي للحياة البرية (كالنباتات وحركة لاندية

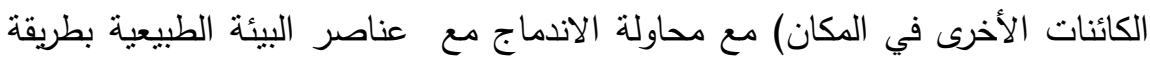
سهله من خلال استخدام الألوان الهادئة في المباني والقريبة من ألوان نلأك العناصر فئهر

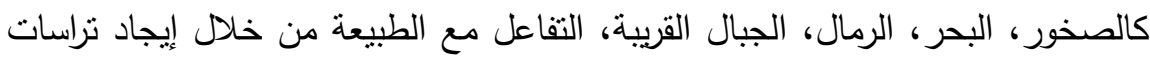

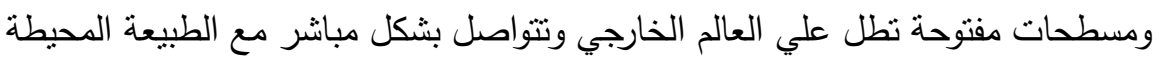

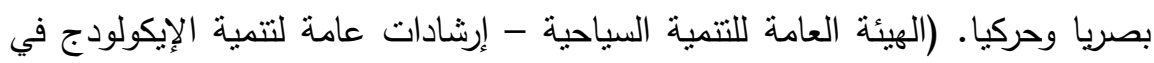

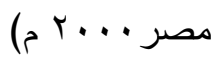
وتختلف مشروعات" الفنادق البيئية " عن مشروعات السياحة التقليدية في عدة اعتبارات

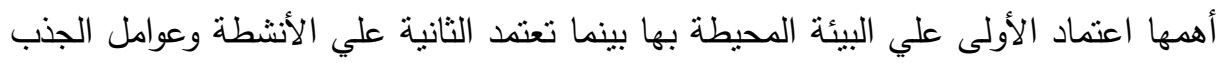
التقليدية ويوضح الجدول التالي بعض الاختلافات بيذهما: 
جدول( (1): مقارنة بين المنشآت السياحية التقليدية والفندق البيئي.

\begin{tabular}{|c|c|c|}
\hline القندق البيئي( النزل البيئية) & المنشآت السياحية التقليلية & نوع المقاومة \\
\hline محلي الطبع. & عالمى الطابع. & طابع التصميح \\
\hline 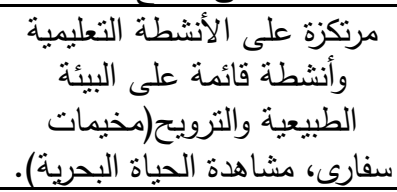 & 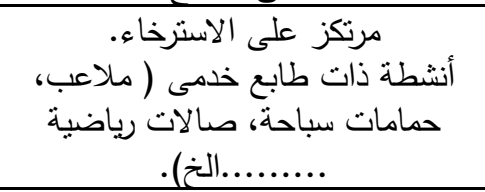 & الألنشانة والتجاربة \\
\hline مندمجة تماماً فى البيئة المحلية. & منعزلة ومنغلقة على نفسها داخل حدود & استراتيجية التخطيط \\
\hline 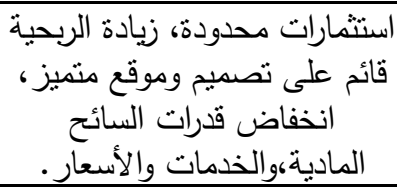 & 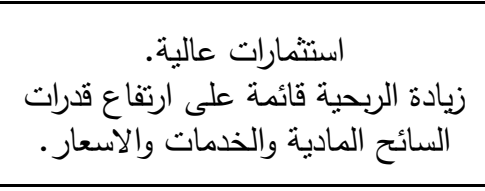 & استراتيجية الاستثمار \\
\hline ما يحيط بالمكان ثم الخذمات. & العوامل الأساسية بالترتيب همى الخدمات بحات بحان. & عوامل الجذب \\
\hline
\end{tabular}

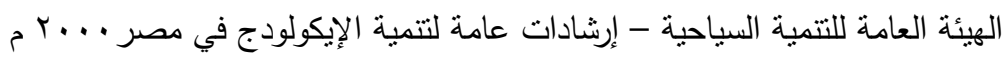

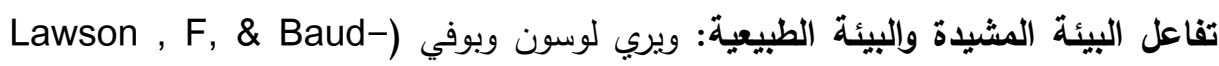

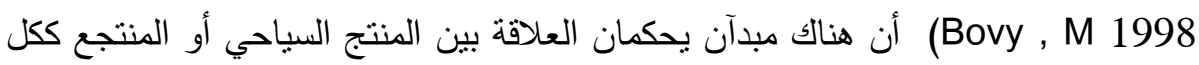
والبيئة الطبيعية وهما:

ا - انه حيثما تكون البيئة الطبيعية جذابة، وتتضمن مناظر طبيعية لها قيمتها فان المقياس

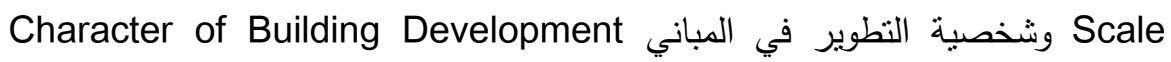
يجب أن يخضعان لهذه المناظر الطبيعية. ץ- انه حيثما تكون البيئة خالية من الجوانب الطبيعية , ففي هذه الحالة يصبح المنتج المقام بها مسهما في الافتقار الجمالي للصورة العامة إذا كان تصميمه علي شاكلة هذه البيئة.

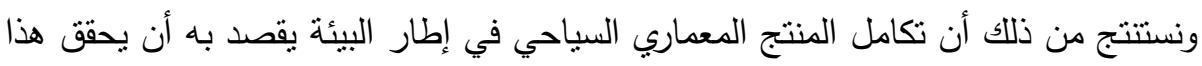
المنتج علاقة طيبة مع البيئة الطبيعية مهما كان شكله أو حجمه أو موقعه.

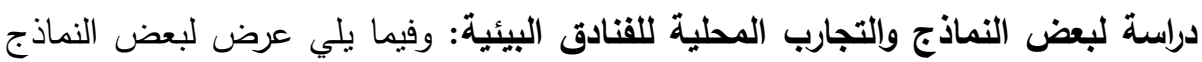

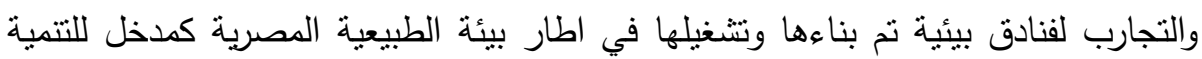
السياحية البيئية التي سبق الاشارة اليها فيما قبل: 
درلسة تحلية لمشروع فندق دبنرت لودج Desert Lodge كنموذج لإحى الفنادق البيئية)(Eco-Lodge) بالواحات الداخلة: • تم بناء الفندق عامץ ..ب وكان الهدف من بنائه أن يكون علي الطراز الإسلادي لقرية

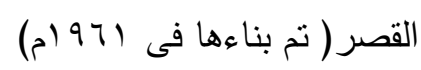

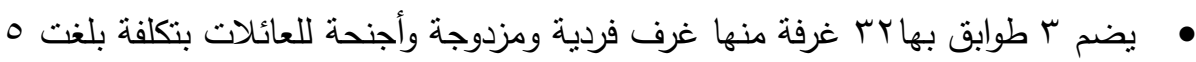

$$
\text { ملايين جنيه }
$$

• الخامات المستخدمة في عملية البناء جميعها من الأحجار والأثجار والنخيل والخامات البيئية كجريد النخل والطوب اللبن المتواجدة بالواحات الداخلة.

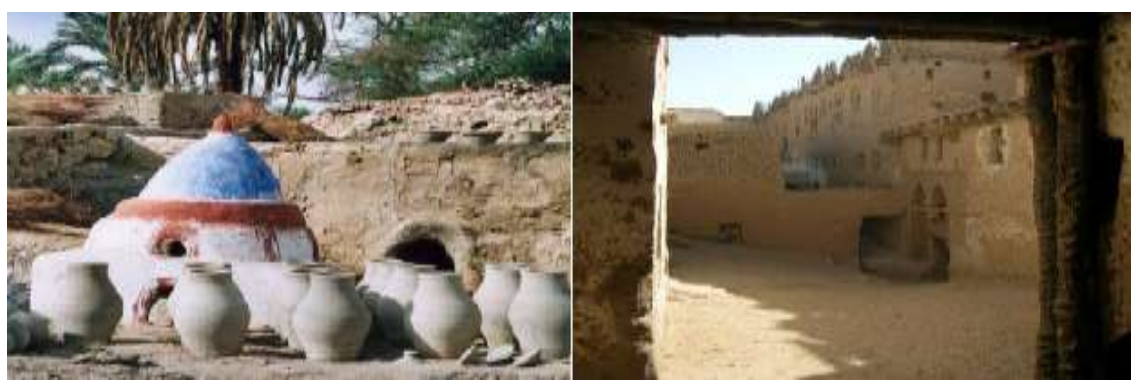

شكل رقم(1): لمدينة القصر التاريخية التي صمم الفندق ليحاكي طرازها المعماري /http://www.desertlodge.net/sightseeing/village

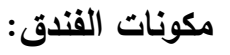
- مطعم رئيسي -كافيتريا- تراس كبير مفتوح - بار - مقهي شعبي- صالات للأنشطة

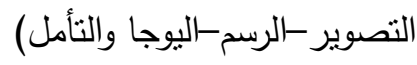
- مرسم ومنحت للفنانين - حمام سباحة به مياه كبرينية للاستشفاء من الينابيع الطبيعية

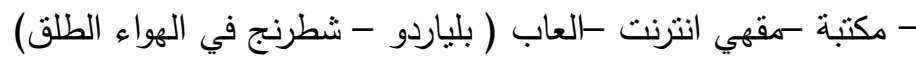
- صالة اجتماعية -تأجير دراجات -بازار للمنتجات المحلية واليدوية 


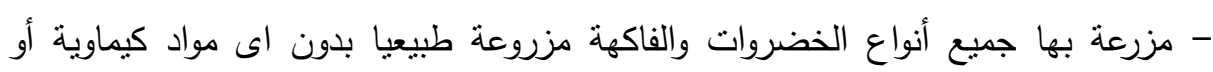

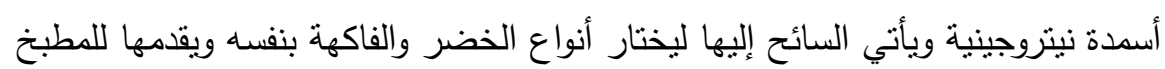
ليتتاول طعامه المفضل

- بئر ارتوازي حفر علي عمق • م مترا مربعا تحت سطح الأرض وبعرض متر ونصف المثر - حدائق للأطفال بها عدد من الألعاب للأطفال من مختلف الأعمار

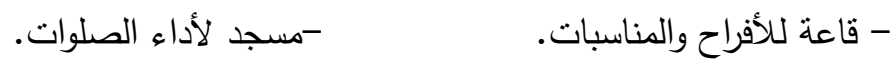

مجلة آثار ( مجلة شهرية ) تعني بالتاريخ والآثار والسياحة بترخيص من المملكة المتحدة :

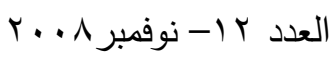

http://www.ndp.org.eg/ar/News/ViewNewsDetails.aspx?NewsID=26771

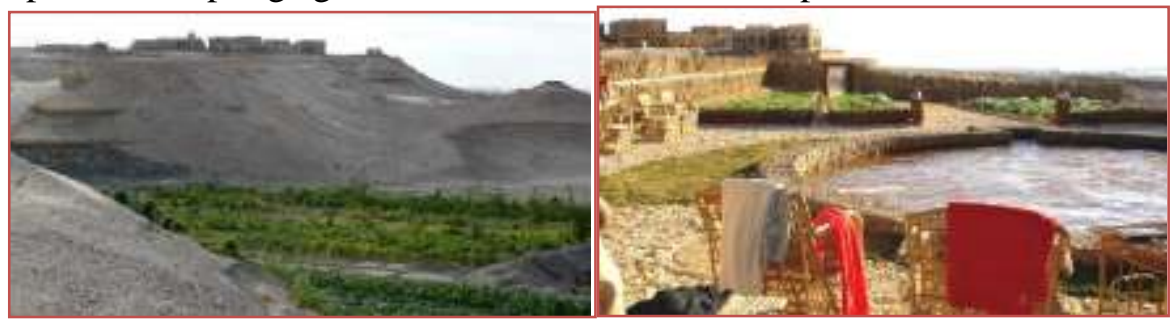

شكل رقم(ץ): حمام السباحة الاسنتفائي بالقرية. شكل رقم(ץ): المزرعة الملحقة بالقرية /http://www.desertlodge.net/ecology/organic-farm

مواد البناء: كافة الغرف مشيدة من خامات طبيعية من البيئة المحلية • • الأسقف من جريد النخيل وجذوع الأشجار

• الأبواب من شجر السنط والثبابيك عبارة عن مشربيات مبنية من أفرع الأثجار الموجودة الائرار بالصحراء والتي كان يستخدمها المعماريون في العصر الأيوبي

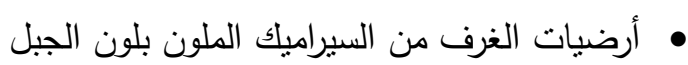

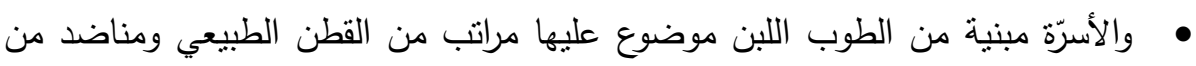

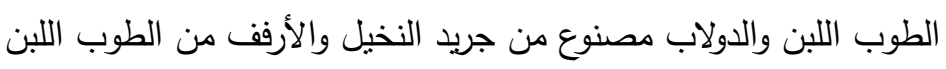


• بالغرفة إناء من الفخار يوضع بجوار التليفون لوضع الثموع به وأمام السرير منضدة

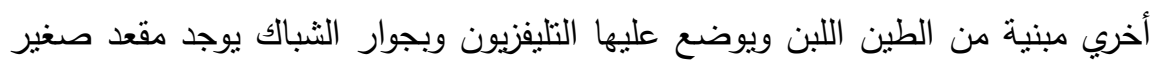
مبني من الطوب اللبن يوضع عليه" قلة "مصنوعة من الفخار

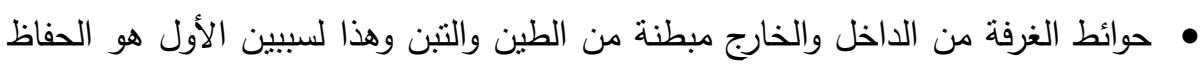

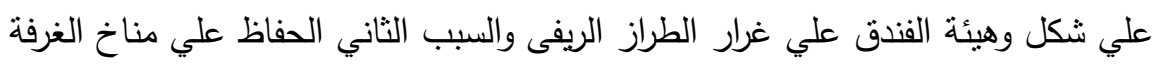
صيفا حيث يجعل من جو الغرفة باردا وفي الثتاء يجعلها دافئة مهما كانت درجة حرارة
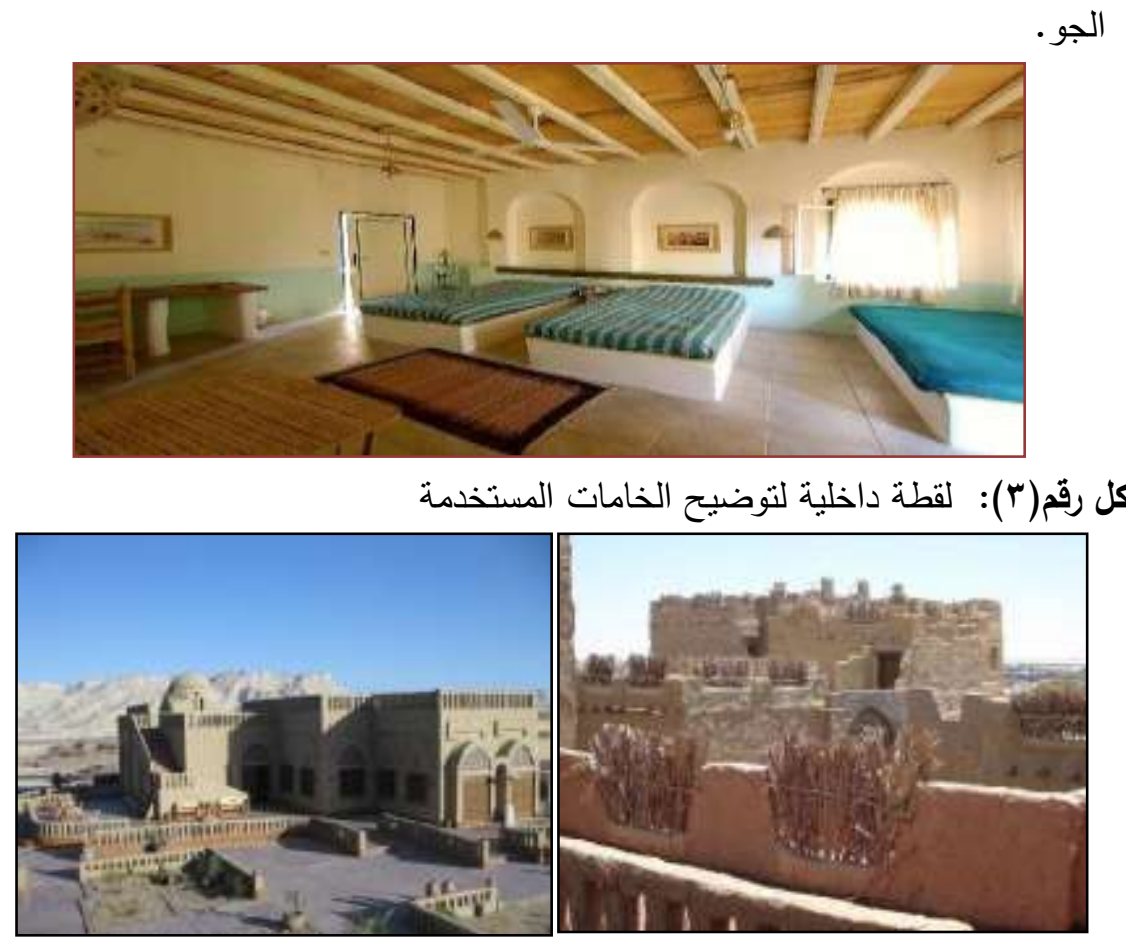

شكل رقم(؛) ) استخدام الخامات الطبيعية و أساليب الإنشاء المحلية في عملية البناء ب - الفندق الحديث أ- البيوت التقليدية

http://www.desertlodge.net/about.html 


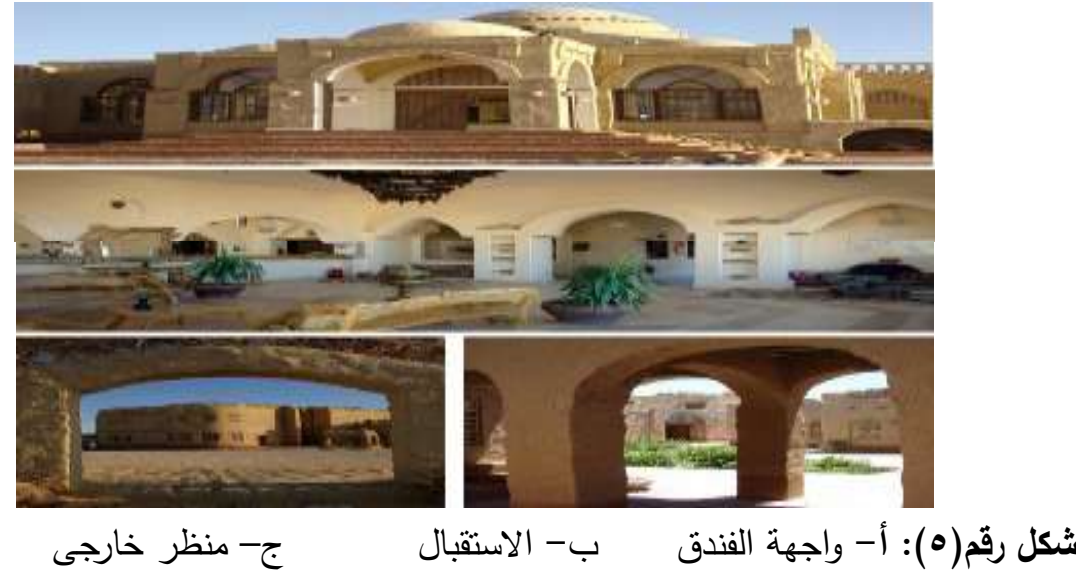

http://www.desertlodge.net/about.html

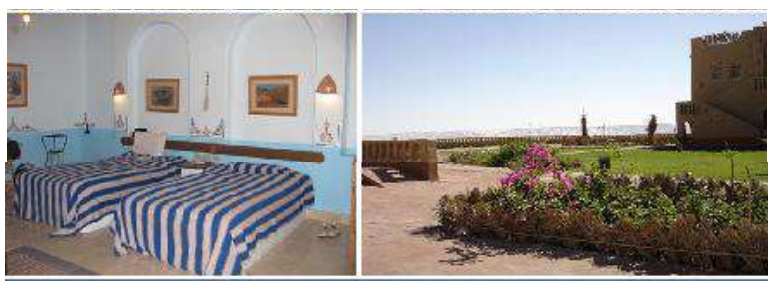

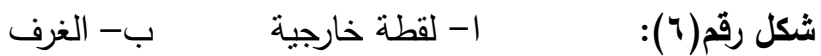

http://www.desertlodge.net/about.html

- دراسة تحليلية لمشروع فندق البابنشال كنموذج لأحلي الفنادق البيئة (Eco-lodge) منطقة سبوه:

• فندق البابنشال كان مشروعاً لإعادة ترميم وتوظيف وإعادة هيكلة المنازل المتهالكة

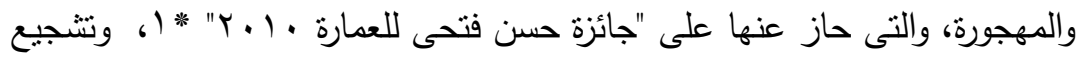
استمرار ترميم المنازل المهورة المحيطة المتقية حول القلعة

' جائزة حسن فتحى للعمارة، أطلقتها مكتبة الاسكندرية ولجنة العمارة بالمجلس الأعلى للتقافة، وتهدف إلى الارتقاء بالعمارة المصرية المعاصرة.

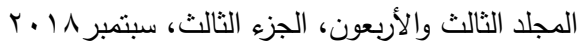


• لم يضف المهندس نعمة الله ( المهندس المصمم) بناء يحاكى أو يقلد الموجود بل قام فقط

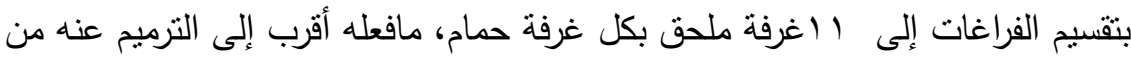
البناء، فالمدخل يوحى بالمربوعة لاستقبال الضيوف أكثر مما يوحى ببهو استقبال النزلاء.

\section{مواد البناء: من منطق احترام البيئة}

• استخدم المهندون الكرشيف (وهو نوع من طبقة سطحية للأرض أصلها الطئه الطفلة السيوية

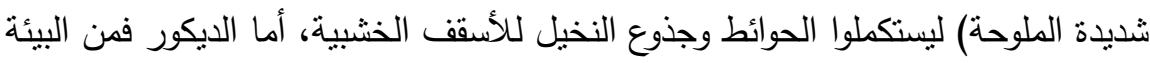
أيضا حيث لا تختلف الغرف عن مثيلاتها فى البيوت السيوية التقليدية.

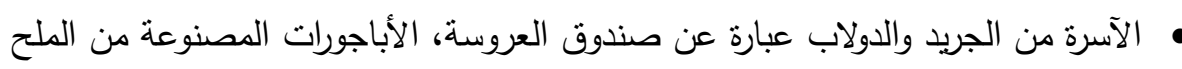

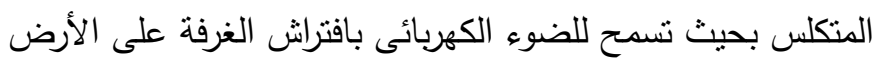

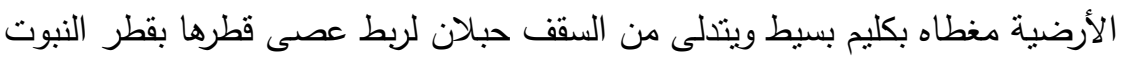
لتعليق الملابس هي في مجملها أفكار بسيطة ومفيدة لا تكلف شيئا سوى بعض هض الخيال

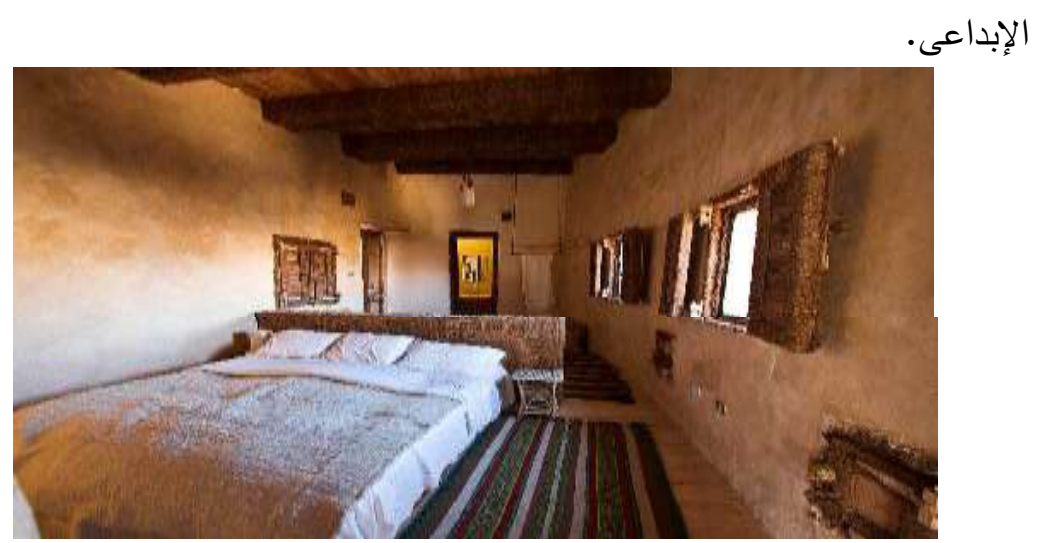

شكل رقم(V): احدي غرف البيت التي تحولت الي غرفة فندقية. www.bonah.org 

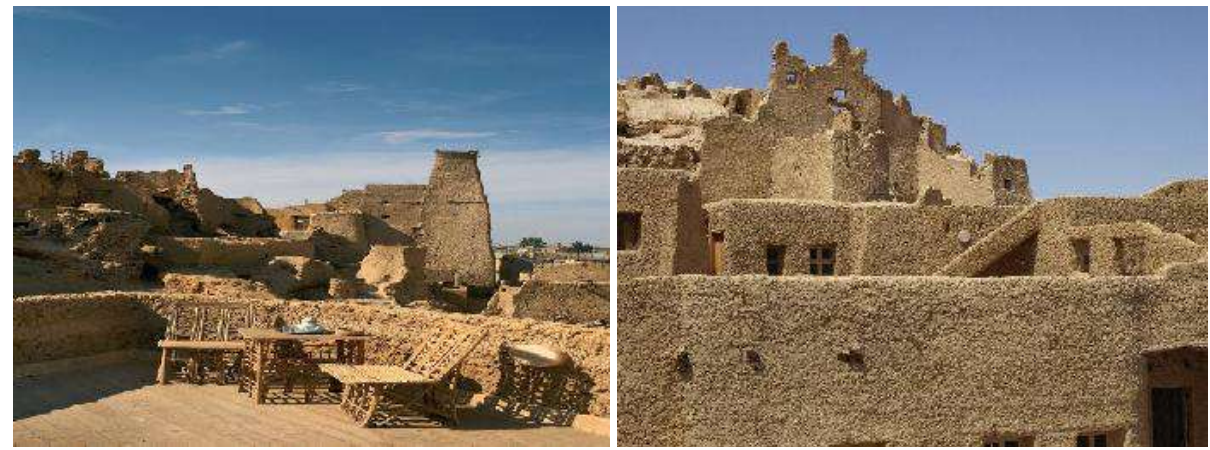

digital.ahram.org.eg

شكل رقم(^): استخدام الاسطح كتراسات للجلوس و مطاعم

دراسة تحليلة لمشروع بيت ضيافة إيكولودج ( بسيوة) كنموذج لأحدي الفنادق البيئة

(Eco-lodge)

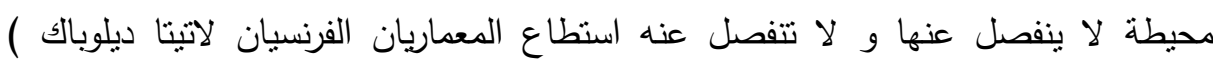

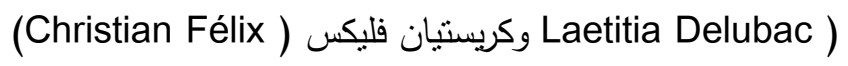

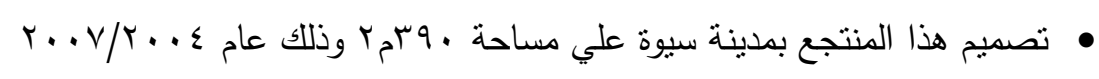

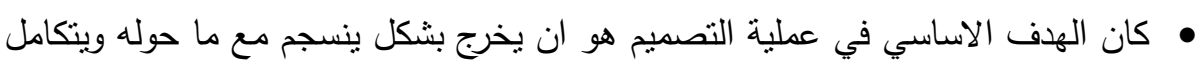

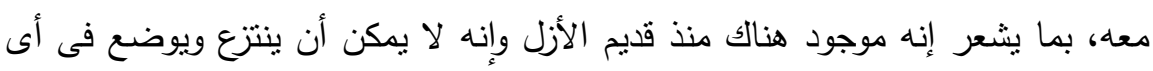
بقعة أخرى فى العالم، أي أنه لا ينتمى إلا لهذا الموقع بخصائصه وأجوائه.

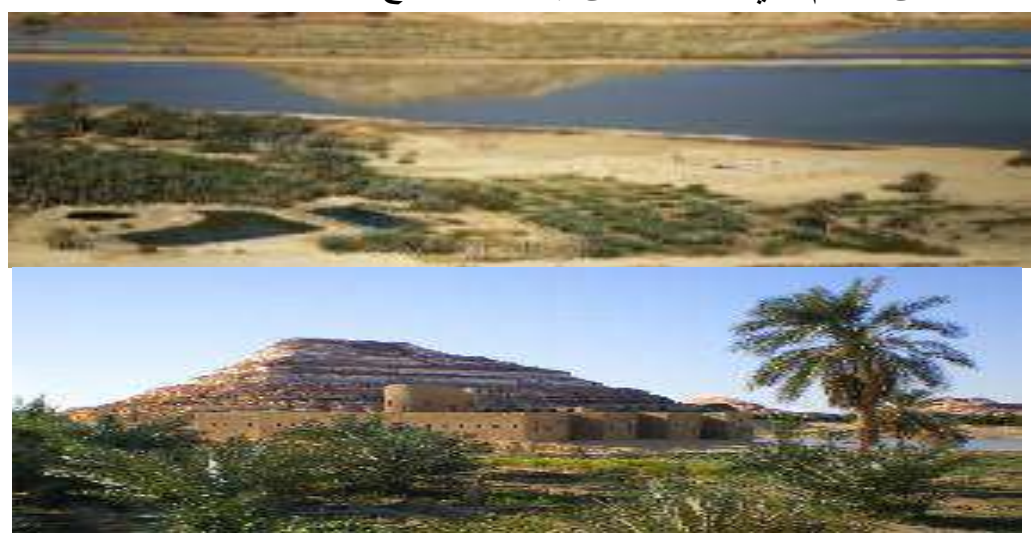

شكل رقم(9): منظر عام للمشروع بواحة سيوة و يظهر الاندماج مع الطبيعة والموقع. www.bonah.org/ المصدر

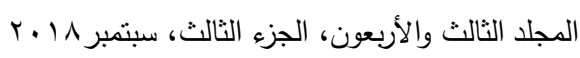


مواد البناء: نم الإستعانة بالسكان الأصليين للمكان

• الحوائط تم بنائها بواسطة حرفيين من الواحة بمادة (الكرشيف) وهى مادة بناء تقلبيدية

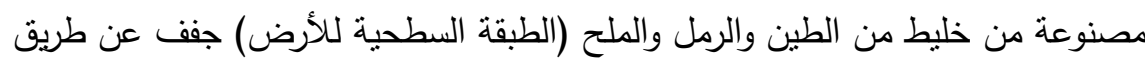

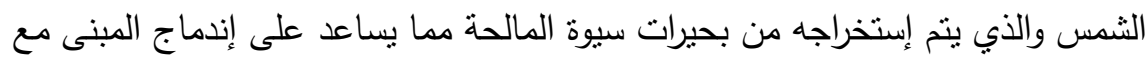
البيئة المحيطة، ويعمل( الكرشيف) كعازل طبيعي للحرارة مما يجعل الهواء داخل المبني في حالة معندلة في المواسم الباردة والحارة.

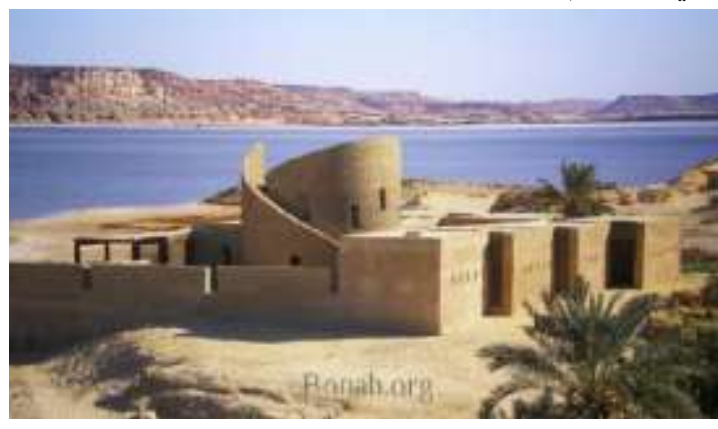

www.bonah.org شكل رقم( • 1 ): لقطة خارجية

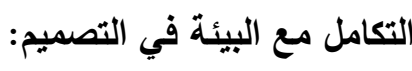
• قرر المعماريان المصممان للمشروع الإستغناء عن كل عناصر التكنولوجيا، فهذا المنتجع يهدف إلى توفير أجواء إنعزالية للزائرين ليأخذهم بعيدا عن صخب الإنغاه عن الحياة ليستمتعوا ببساطة

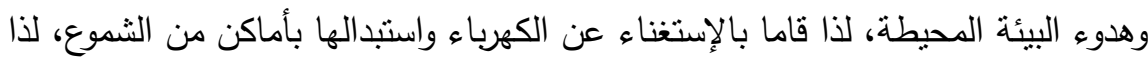

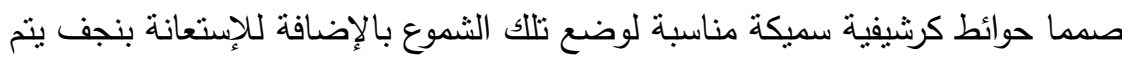

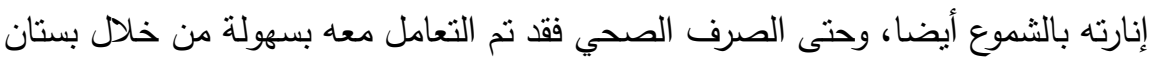

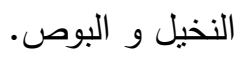


دعاء الحسن على وآخرون

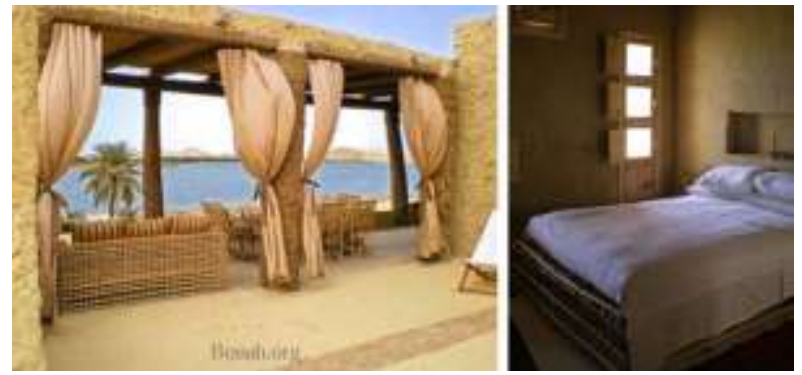

شكل رقم(1 1 ): يستخدم الخامات المحلية في صنع الأثاث

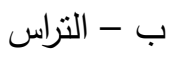

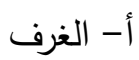

Www.bonah.org/

• تم توجيه غرفة المعيشة ناحية الثمال لحمايتها من أثنعة الثمس، وفى الواجهة الجنوبية

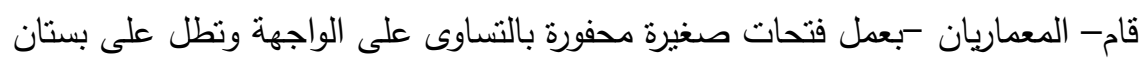
من النخيل لحمايتها من الرياح الرملية.
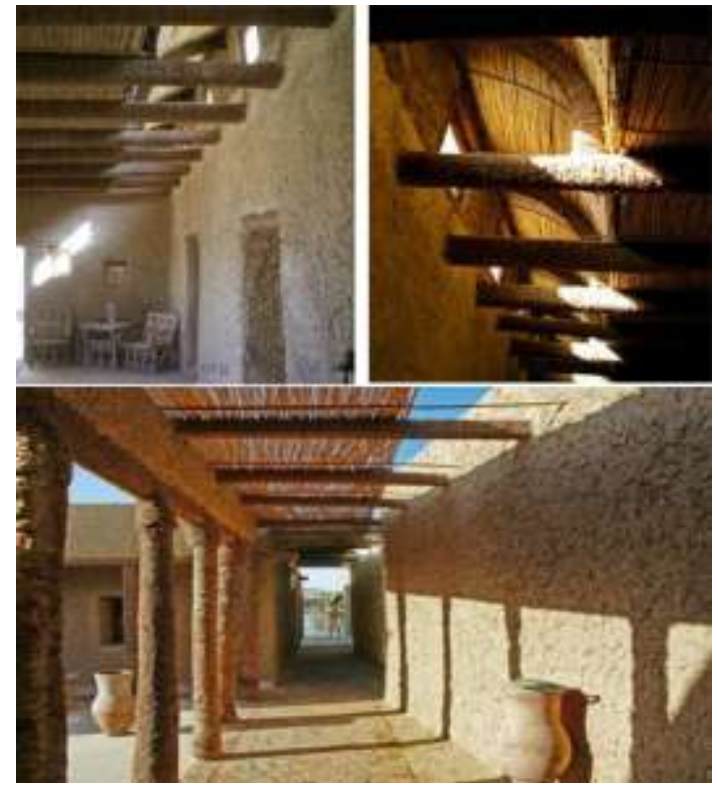

شكل رقم(Y I ): خامات البناء الطبيعية والمفردات المعمارية الجميلة المستخدة لها من قش و من كرشيف و جذوع النخيل

http://www.bonah.org/news-extend-article-538.html

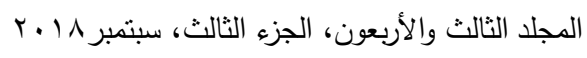




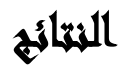

توصلت الدراسة إلى عدد من النتائج يمكن صياغتها فيما يلى:

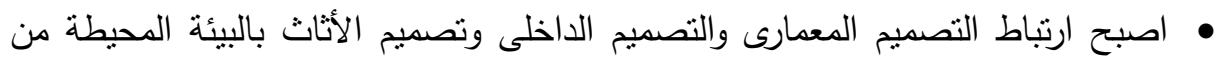

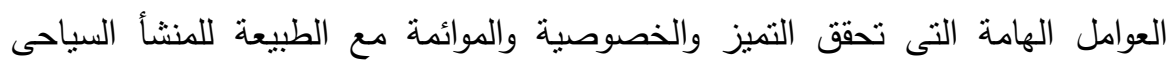

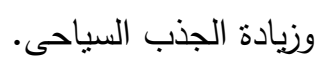

• نساهم عناصر البيئة الطيعية إلى حد كبير فى تحديد معالم التصميم الدعمارى وطبيعة

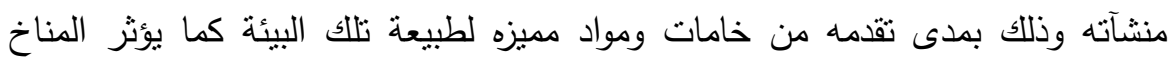
والعوامل الجوية الدتغيرة فى نظم الانثاء وطبيعة التصميم المعمارى.

\section{اللجوصياهت}

ا- الحرص على تطبيق أسس التصميم البيئى فى مجال العمارة والتصميم الداخلى بصورة

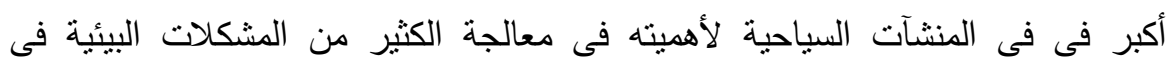

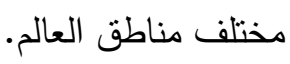
r- الاهتمام بتصميمات المنثآت السياحية وجعلها أكثر ملائمة شكلياً ووظيفياً عن طريق الربط بين الفراغات الداخلى والمحيط الخارجى بشكل ملائم بيئياً. r- التأكيد على أن المحميات الطبيعية تثنل ثروات رئيسية أساسية لعملية التتمية المستدامة

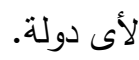
ع- دعم الأبحاث والدراسات المتخصصة فى المجالات النى تحافظ على البيئة الطبيعية والسياحة البيئية من قبل الجهات المتخصصة.

\section{المرالئ}

الهيئة العامة للتتمية السياحية - إرشادات عامة لتتمية الإيكولودج في مصر ... Y م digital.ahram.org.eg http://www.bonah.org/news-extend-article-538.html 
http://www.desertlodge.net/about.html

http://www.ndp.org.eg/ar/News/ViewNewsDetails.aspx?NewsID=2677

1

Lawson , F, \& Baud-Bovy , M Tourism and Recreation Development,A Hand Book of Physical

www.bonah.org/

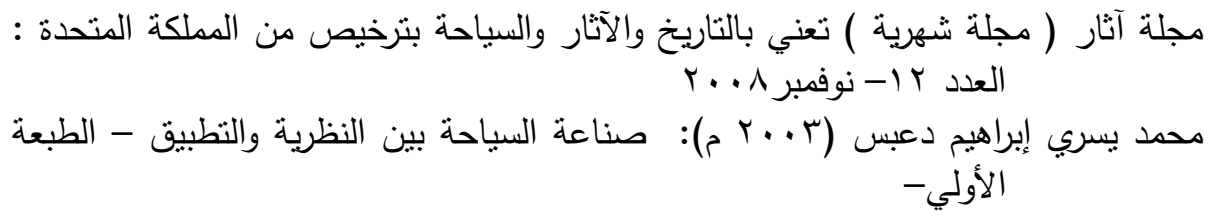

\title{
SUSTAINABLE ECO-TOURISM IN EGYPT
}

Ali, Doaa, E..$^{(1)}$; Mouharam, A. Y.(1) and Rady, A. ${ }^{(2)}$

1) Institute of Enviromental Studies and Research-Ain, Shams University 2) Chairman of Port Ghaleb Resort_CO

\begin{abstract}
In order to use the available potentialities and elements to drive the development of tourism in Egypt, mechanisms should be put in place to regulate and control this process and set priorities to save time and effort in addition to directing the state investments in the right direction. The development process, (As some regions in Egypt have potentials and advantages that exceed many other regions but also lack many other elements necessary and important for the development process.)

The selection of regions for tourism development is important in the development process. Not every region is suitable for tourism and recreational development and achieve economic feasibility, and the good choice of location is an important element in the development process itself.
\end{abstract}

$$
\text { المجلد الثالث والأربعون، الجزء الثالث، سبتمبر 1 ـ r }
$$

